\title{
CAMINHOS PARA O APRIMORAMENTO DA GESTÃO DE POLÍTICAS PÚBLICAS EM ÁREAS DE FRONTEIRA: UMA ANÁLISE MULTINÍVEL ${ }^{1,2}$
}

\author{
Caroline Krüger ${ }^{3}$ \\ Nino Rafael Medeiros Krüger ${ }^{4}$ \\ Cláudia Souza Passador ${ }^{5}$ \\ Adriana Cristina Ferreira Caldana ${ }^{6}$
}

\section{INTRODUÇÃO}

Os sistemas de gestão pública para as fronteiras carecem de abordagens que contemplem as necessidades peculiares desse território, tendo em vista o imbricado conjunto de características subjacentes a essas regióes e os desafios colocados a elas na atualidade. As reflexóes nesse âmbito nortearam as análises da tese Da avaliação de impacto à governança transfronteiriça: contribuiçôes para o aperfeiçoamento da gestão de políticas públicas (Krüger, 2019), que buscou responder à seguinte pergunta de pesquisa: como aprimorar a gestão de políticas públicas em áreas de fronteira?

Com esse escopo, este ensaio faz uma resenha dos principais achados da tese em pauta. Para isso, logo após esta breve introdução (seção 1), aborda-se o contexto atual das fronteiras mundiais (seção 2). Em seguida, comentam-se os avanços e os desafios das políticas públicas fronteiriças no Brasil (seçáo 3). Na sequência, apresentam-se o porquê da governança transfronteiriça (seção 4) e os resultados da tese em uma perspectiva multinível (seção 5). $\mathrm{O}$ artigo finaliza com algumas considerações (seção 6).

\footnotetext{
1. DOI: http://dx.doi.org/10.38116/brua22art6

2. Este ensaio analítico é fruto da pesquisa de doutoramento em administração de organizações pela Universidade de São Paulo (USP) da autora Caroline Krüger, integrando as pesquisas do Global Organizational Learning and Development Network (Golden) for Sustainability Brazil; e do Centro de Estudos em Gestão e Políticas Públicas Contemporâneas da USP (GPublic/USP) com o Instituto de Estudos Avançados-Polo Ribeirão Preto (IEA-RP) da USP.

3. Pesquisadora doutora na Diretoria de Estudos e Políticas Regionais, Urbanas e Ambientais (Dirur) do Ipea.

4. Doutorando e mestre em políticas sociais e direitos humanos pela Universidade Católica de Pelotas (UCPEL).

5. Professora adjunta no Departamento de Administração da Faculdade de Economia, Administração e Contabilidade de Ribeirão Preto (FEA-RP) da USP.

6. Professora adjunta no Departamento de Administração da FEA-RP/USP.
} 


\section{CONTEXTO ATUAL DAS FRONTEIRAS MUNDIAIS}

O processo de globalização fomentou uma perspectiva de desaparecimento progressivo das fronteiras mundiais diante da promessa de fluidez e integração entre as naçôes; contudo, mais de 26 mil quilômetros de fronteiras políticas foram traçados somente na Europa e na Ásia nas últimas duas décadas, e outros tantos têm sido palco de conflitos (Foucher, 2009). As fronteiras, no entanto, são muito mais que hostilidades e contradiçôes relatadas nos meios midiáticos em geral; são marcas de complementaridade e permeabilidade, são nós expressivos de "ligação entre malhas territoriais distintas, elos agudos da integração", marcadas por um processo "paradoxal de desmantelamento e reconstrução" (Oliveira, 2015, p. 235).

Esse processo de reconstrução da fronteira meramente como limite tem sido chamado de "desfronteirização", que se expressa pela tendência de controle permanente e fechamento seletivo de fronteiras (Oliveira e Dorfman, 2015), sendo justificada pela segurança, mas, na verdade, apresentando-se como o reforço dos processos históricos de desigualdade entre os países (Kramsch, 2002). Um estudo cartográfico das pesquisadoras Elisabeth Vallet e Stéphane Rosière demonstra que cerca de $80 \%$ da riqueza e apenas $20 \%$ da população estão no interior dos países ricos, como Estados Unidos, Canadá, Austrália, Japão e grande parte dos países europeus, onde tem sido vivenciado um fechamento físico e político (Oliveira e Dorfman, 2015). Contrariamente, os demais $80 \%$ da população estâo fora desses "muros", com apenas 20\% das riquezas (Pêgo et al., 2020a).

Esse cenário tem sido reforçado por conflitos, atentados, crises econômicas e de refugiados, provocando um fluxo de algumas centenas de milhares de pessoas, principalmente do norte da África e do Oriente Médio para a Europa; da América Central para os Estados Unidos e o Canadá; e mais contemporaneamente da Venezuela para a Colômbia e o Brasil (ACNUR, 2019; Doocy et al., 2019).

Além das questôes em pauta, com consequências na falta de disposiçẫo de serviços públicos e emprego, as fronteiras mundiais são, em sua maioria, palco de açôes do Estado focadas sumariamente no combate ao narcotráfico e ao contrabando, que fomentam uma visão estereotipada da regiáo e "desprezam os nexos de cooperação e integração cotidiana do território" (Oliveira, 2015, p. 249). Diferentemente dessa visão, as fronteiras em geral são "ambientes extremamente dinâmicos e criativos, mais cosmopolitas e tolerantes", onde a maioria das pessoas gosta de viver (Oliveira e Dorfman, 2015). Contudo, as assimetrias econômicas e sociais e os desafios ambientais, institucionais e legais formam um arcabouço complexo, necessitando de respostas específicas para o desenvolvimento dessas regióes que as agendas políticas tradicionais náo têm conseguido promover (Kramsch, 2002; Zumbusch e Scherer, 2015).

Como resultado desse panorama, a pauta fronteiriça tem ocupado destaque nas discussōes internacionais (Mikhailova, 2014; Schmidt, 2005) e nacionais (Pêgo et al., 2017; 2018). Assim, tem-se argumentado que as políticas públicas, entendidas como o Estado em ação (Jobert e Muller, 1987), podem ser construídas com variados formatos e instrumentos

7. 0 termo "desfronteirização" é usado por Oliveira e Dorfman (2015) aludindo à tentativa de desmantelamento da fronteira, considerando que ela existe a partir do outrem (país/cidade limítrofe etc.). A negação da funcionalidade dessas regiões por meio de um fechamento cauteriza as relações de reciprocidade entre as localidades lindeiras. Os autores complementam ao afirmar que os países se comportam como condomínios de luxo, implementando postos avançados/externos de controle de documentação e de concessão ou não de vistos. Como exemplo, há o caso da Europa, que fez do norte da África uma fronteira, e dos Estados Unidos, onde a migração para o país é controlada no México, entre outros (Oliveira e Dorfman, 2015). 
para ultrapassar acirramentos, proporcionando pontes entre os países que estão próximos territorialmente, mas distantes em suas ações governamentais (Cruz, 2014; Pikner, 2008; Spacek, 2018).

\section{PANORAMA DAS POLÍTICAS PÚBLICAS FRONTEIRIÇAS NO BRASIL: AVANÇOS E DESAFIOS}

No contexto nacional, as açôes públicas para a fronteira são resultado de um processo histórico fundado na preocupação do Estado com a garantia de sua soberania desde o Período Colonial. Nos anos 1970, a regiâo foi caracterizada como zona de interesse especial pelo governo federal, quando passou a ser identificada como Faixa de Fronteira (FF), um espaço territorial dotado de complexidade e peculiaridades que a torna singular em relação ao restante do país, sendo instituída sua conformação territorial na Lei no $6.634 / 1979$, com função estratégica de área de segurança territorial (Brasil, 2005).

Posteriormente, na Constituição Federal de 1988, foi avalizada a disposição do ideal "segurança, controle e proteção", limitando, assim, as oportunidades de desenvolvimento local. Desde então, a preocupação com a segurança e a soberania do território nacional tem alicerçado discussóes acerca do desenvolvimento e, concomitantemente, promovido a percepção de que, para haver segurança, faz-se necessária a vivificação da região focando a geraçáo de emprego e renda (Brasil, 2010).

Importante esclarecer que essa faixa de terra com $150 \mathrm{~km}$ de largura, contados a partir do limite internacional, estende-se de norte a sul do país, ao longo dos 16 mil quilômetros de divisas com dez dos doze países da América do Sul. No total, abrange 586 municípios em onze estados da Federação, dos quais 121 são limítrofes, ou seja, situam-se na linha de fronteira (IBGE, 2018). Nessas localidades, vivem mais de 11,7 milhóes de pessoas (IBGE, 2019), sendo consideradas regióes de necessidades latentes, carentes de ações consistentes, que promovam o desenvolvimento (Brasil, 2016b; Machado, 2005; Pêgo et al., 2018; Torrecilha, 2013).

Uma das características marcantes da FF brasileira é a baixa densidade demográfica, em grande medida devido à concentraçáo do desenvolvimento nas regiôes próximas ao litoral do Brasil, associada ainda às grandes distâncias e às dificuldades de comunicaçáo com os principais centros decisórios. Isso fez com que, desde sua criaçáo, experimentasse um relativo isolamento, sendo-lhe conferidas açóes públicas pontuais de ocupação territorial e implantação de bases militares, o que a colocou à margem das políticas centrais de desenvolvimento $\mathrm{e}$ limitou projetos de integração (Brasil, 2005; 2009).

Mesmo pontualmente e com restriçóes, a FF foi alvo de políticas públicas desde a década de 1980, com a instituição do Programa Calha Norte (Krüger et al., 2017). Na década de 1990, apesar da estagnação política (Cargnin, 2014), a retomada da perspectiva de desenvolvimento da regiáo se deu com a institucionalização da Política Nacional de Desenvolvimento Regional (PNDR), consubstanciada em 1999 mediante o Programa de Desenvolvimento da Faixa de Fronteira (PDFF), do Ministério da Integração Nacional (MI), ${ }^{8}$ iniciativa posteriormente reestruturada, em 2005 (Brasil, 2005).

Tal reestruturação se deu a partir de uma avaliação negativa do PDFF (1999-2002) em virtude da alocação de recursos em medidas pontuais, sem diretrizes claras, desconsiderando as diferenças sub-regionais em termos de desenvolvimento e integração fronteiriça (Brasil,

8. Atual Ministério do Desenvolvimento Regional (MDR). 
2005), resultando na definição da região como área especial de planejamento para a promoção de políticas públicas de desenvolvimento regional (Machado, 2005). A relevância da agenda política conduziu à definição de uma nova diretriz ao PDFF, inserindo a orientação estratégica de desenvolvimento regional e integração da América do Sul (Brasil, 2005). O programa, contudo, teve dificuldades orçamentárias, uma vez que seus recursos eram, na maior parte, oriundos de emendas parlamentares, o que dificultou suas açóes no território e fez com que fosse descontinuado (Gimenez, 2015; Scherma, 2015).

Nesse período, outros programas também foram implementados na região, nas áreas de educação, saúde e integração (Krüger et al., 2017), como o Integração Sul-Americana, que "visava fortalecer a integração regional como um todo", porém, "o programa não era prioritário no governo federal e não se mostrou efetivo" (Scherma, 2015, p. 213). Além disso, houve a proposiçẫo do Plano de Desenvolvimento Regional e Sustentável para a Faixa de Fronteira - Plano Brasil Fronteira, mas, segundo Scherma (2015, p. 213), a "falta de apoio de outros ministérios foi fundamental para que o mesmo não se institucionalizasse".

Em resumo, houve programas que entraram na agenda e não chegaram a se efetivar; outros ainda foram implementados, mas apresentaram diversos entraves que comprometeram os seus resultados, tais como: contingenciamento de recursos, descontinuidade política, deficiência de apoio e coordenação, carência de monitoramento e avaliação, entre outros (Brasil, 2016b; Krüger et al., 2017). Este último fator está, em grande medida, relacionado à falta de disposição de dados oficiais, o que retrata ainda outro desafio: a falta de transparência na disposiçẫo de informaçôes (Krüger, Dantas e Castro, 2018).

Em 2010, alguns desses resultados já eram percebidos, como o estudo do Comitê de Articulação Federativa que identificou que vários desses programas foram implementados de forma desarticulada (Brasil, 2010). Tal acontecimento repercutiu na criação da Comissão Permanente para o Desenvolvimento e a Integração da Faixa de Fronteira (CDIF), que, entre seus objetivos, propôs medidas e gerenciamento das açóes do governo federal na referida localidade (Brasil, 2010; Gimenez, 2015).

Por conseguinte, após a criação da CDIF, agregando representantes dos diferentes ministérios e membros convidados, foram instituídos os núcleos de fronteira, que, em sua maioria, organizam-se a partir de decretos estaduais que designam seus membros. Seus objetivos visam identificar e priorizar os problemas para a atuação do poder público e dialogar com instituiçóes atuantes na FF do respectivo estado para sistematizar as demandas locais, analisar propostas de açôes e formular Planos Regionalizados de Desenvolvimento e Integração Fronteiriços (PDIFs) (Brasil, 2010).

Outra importante iniciativa para a gestão do território fronteiriço, que esbarra em diversos desafios, foi a instituição das cidades gêmeas pelo governo federal. Tais cidades se caracterizam como "adensamentos populacionais cortados pela linha de fronteira - seja esta seca ou fluvial, articulada ou náo por obra de infraestrutura, que apresentam grande potencial de integração econômica e cultural, assim como manifestaçôes 'condensadas' dos problemas característicos" da regiáo, mas "que nesse espaço adquirem maior densidade, com efeitos diretos sobre o desenvolvimento regional e a cidadania" (Brasil, 2010, p. 21). Segundo a Portaria no 213/2016 do MDR, havia 32 cidades gêmeas instituídas em 2016, sendo viabilizada a criação de Cáceres e San Matías em 2019 (Pêgo, Moura e Nunes, 2019). O reconhecimento da diferenciação dessas localidades demonstra sua relevância no contexto fronteiriço nacional. 
Com esse cenário, é fundamental esclarecer que, apesar das importantes iniciativas citadas, percebe-se três grandes desafios no que se refere às instituiçôes fronteiriças já formalizadas: a CDIF, por não ter recurso orçamentário específico para executar na fronteira, tem suas ações limitadas à articulação; os comitês de fronteira, que seriam "o espaço institucional de articulação local do poder público e da sociedade civil de ambos os países acerca das demandas e questôes transfronteiriças (...), possuem iniciativas adotadas pontualmente, sem continuidade ou permanência verificada e sem estrutura institucionalizada" (Gimenez, 2015, p. 206); e, ainda, a cooperação entre os estados e municípios fronteiriços e seus homólogos vizinhos, como as cidades gêmeas, é amparada por lei apenas parcialmente, dado que as iniciativas de gestão compartilhada, como compras conjuntas, participaçáo em consórcios etc., não são protegidas por lei, o que dificulta a resolução de problemas comuns em territórios transfronteiriços (Brasil, 2016c; Pêgo et al., 2020a; Scherma, 2015).

Diante desse panorama, do ponto de vista político-administrativo, torna-se fundamental avaliar e discutir a organizaçáo e o desempenho das açóes públicas efetuadas na região de fronteira, com vistas ao enfrentamento das vulnerabilidades locais e à promoção do desenvolvimento. ${ }^{9}$ Além disso, os resultados apontam a necessidade de governança, visto que esta, em áreas de fronteira, tem sido percebida como necessária para coordenaçáo de políticas ou gerenciamento de interdependências territoriais para o alcance de melhores resultados (Leibenath, 2007; Perkmann, 2007; Zumbusch e Scherer, 2015), como mais bem discriminado na seção a seguir.

\section{POR QUE A GOVERNANÇA TRANSFRONTEIRIÇA?}

As ações para a resolução de desafios transfronteiriços abrangem uma série de atores e instituiçôes públicas, privadas e sociais, que, separadamente, dificilmente dariam conta desse enfrentamento (Oddone, Vázquez e Oro, 2018). Para articulação do território visando à resolução de problemas comuns, a literatura tem apontado a necessidade de sistemas de governança transfronteiriça (Pikner, 2008; Zumbusch e Scherer, 2015), que se caracterizam como a construção de arranjos de coordenação que transcendam os limites impostos pela máquina pública (Gualini, 2003; Kramsch, 2002; Durand e Nelles, 2014).

Uma vez que a governança pode ser abordada sob diferentes prismas, Gereffi (2005) a identifica em níveis: $i)$ no macro, estaria a governança econômica global, caracterizada pelas normas, regras, regimes e acordos bilaterais/multilaterais; ii) no intermediário, estaria a governança pública (país) e a governança corporativa (empresas); e iii) no microeconômico, o autor cita que a governança pode adquirir diversas performances, com ativistas ambientais, grupos sociais, trabalhistas etc.

A governança transfronteiriça, no entanto, não se limita à esfera pública ou corporativa, ou, ainda, à área ambiental, social ou trabalhista. Antes, permeia os diferentes níveis e áreas, caracterizando-se como a construção de arranjos de coordenação que integram diferentes setores e instituiçóes (Durand e Nelles, 2014; Gualini, 2003; Kramsch, 2002), baseada em planejamento holístico do território, discutida e formulada com atores não governamentais

9. Com esse entendimento, o então Ministério da Integração Nacional firmou uma parceria de pesquisa com o Ipea para avaliação dessas ações. Porém, em razão de os recursos serem fundamentalmente repassados às localidades por emenda parlamentar e por não haver histórico das ações registradas e dados para avaliação, o Ipea encontrou caminhos em um esforço qualitativo de levantamento de dados por meio da realização de oficinas, reunindo diversos atores estrategicamente envolvidos com o tema, para avaliação dessas políticas (Pêgo et al., 2017; 2018; 2020a). 
locais, amparada pela cooperação entre os diferentes níveis de governo dos Estados limítrofes na fronteira (Perkmann, 2007; Pikner, 2008; Scott, 2000).

Nesse contexto é importante ainda ressaltar que, como fomento à governança e cooperação para o desenvolvimento entre os países na atualidade, foi estabelecida em 2015 a Agenda 2030 para o Desenvolvimento Sustentável (GTSCA2030, 2019). A Agenda se desdobra em dezessete objetivos e 166 metas, estando entre eles: a erradicação da miséria; saúde e bem-estar; educação de qualidade; emprego digno e crescimento econômico; redução das desigualdades, perpassando cidades sustentáveis; combate às alteraçóes climáticas; e paz, justiça e instituições fortes. O pivô para o alcance desses objetivos é o ODS 17, que aponta a centralidade da governança mediante o fortalecimento dos meios de implementação e revitalização das parcerias globais para o desenvolvimento sustentável (Naçóes Unidas Brasil, 2015).

Apesar da contribuição nessa pauta de organizaçôes internacionais e do desenvolvimento do tema há cerca de três décadas nos acordos e políticas públicas na Europa, articulando seus Estados-membros para gestão e resolução de problemáticas em âmbito transfronteiriço, na América do Sul são raras as iniciativas para governança transfronteiriça (Oddone, Vázquez e Oro, 2018). Na fronteira brasileira com os dez Estados lindeiros, pontuais avanços são percebidos mesmo com os esforços por meio dos blocos econômicos e iniciativas locais de consórcios transfronteiriços (Henrichs e Meza, 2017).

Ainda que na Europa a governança transfronteiriça encontra-se institucionalizada por meio da política de Cooperação Territorial Europeia (CTE $)^{10}($ Kramsch, 2002), esse processo possui diversos entraves (Pikner, 2008; Spacek, 2018), havendo claramente uma falta de estudos que abordem de uma forma abrangente os seus elementos limitantes ou potencializadores. Além disso, a literatura sobre o tema tem demonstrado polissemia problemática do termo (Dupeyron, 2017), carência de revisões sistemáticas que sintetizem os resultados dos estudos já realizados (Mikhailova, 2014; Pikner, 2008; Schmidt, 2005) e falta de perspectivas práticas que vão além de pesquisas com abordagens específicas do processo (Deppisch, 2012; Hernández-Ramírez, 2017) ou estudos de caso (Evrard, 2016; Spacek, 2018; Svensson, 2015).

\section{RESULTADOS DO ESTUDO EM UMA PERSPECTIVA MULTINÍVEL}

Desse modo, o desenho teórico e metodológico da tese resenhada em perspectiva analítica aqui esboçada foi desenvolvido de modo a suprir as lacunas identificadas durante a revisão da literatura e o trabalho de campo, no intuito de aproximar os resultados da pesquisa às necessidades informacionais dos tomadores de decisão, buscando-se também atender às recomendaçôes dos diversos atores inquiridos. Assim, a proposta de uma tese em escopo multinível (Aguinis, Gottfredson e Culpepper, 2013), contendo três estudos com perspectivas e contribuições complementares, conjuga elementos que visam atender às demandas levantadas, por meio de um processo dinâmico de interaçóes dialógicas entre constataçóes teóricas e empíricas, com a finalidade de conferir ao trabalho uma lógica coesa, em torno

10. A política CTE é também conhecida como Interreg, sendo financiada pelo European Regional Development Fund (ERDF); apresenta-se como um quadro para a implementação de ações conjuntas e intercâmbios de políticas entre os intervenientes nacionais, regionais e locais de diferentes Estados-membros (Leibenath, 2007). A CTE possui programas em três vertentes de cooperação: transfronteiriços (nível A), transnacionais (nível B) e inter-regionais (nível C), sendo sucedida por meio de cinco períodos de programação: INTERREG I (1990-1993); INTERREG II (1994-1999); INTERREG III (2000-2006); INTERREG IV (2007-2013); e INTERREG V (2014-2020) (Zäch e Pütz, 2014). Para mais informações, ver:<https://www.interregeurope.eu/>. 
de um eixo condutor coerente e relevante, buscando contribuir para estudiosos e gestores de políticas públicas transfronteiriças.

Assim, partindo-se da premissa que as fronteiras são territórios marcados pela dualidade, uma vez que são indispensáveis marcadores de identidade, autoconsciência e diversidade e, ao mesmo tempo, representam historicamente zonas de conflito/crises políticas e mutabilidade (Foucher, 2009; Oliveira, 2015), com desafios prementes na atualidade (Dupeyron, 2017), e que tais territórios representam áreas que demandam uma gestão com características particulares, o objetivo de pesquisa que norteou as reflexóes no âmbito da tese em síntese foi identificar diretrizes para o aprimoramento da gestão de políticas públicas em áreas de fronteira.

Para o alcance desse objetivo, a tese em pauta se desenvolveu em níveis de análise esboçados por meio de três estudos. No primeiro, realiza-se uma avaliação do projeto Sistema Integrado de Saúde das Fronteiras (SIS-Fronteiras), criado pelo Ministério da Saúde do Brasil para a melhoria da qualidade de vida na FF. Importante esclarecer que essa política foi selecionada entre as demais para avaliaçáo porque foi a única que apresentou dados quantitativos disponíveis. Sendo assim, a análise foi realizada em duas etapas. Primeiro, para dimensionar o impacto do projeto, foram analisados os indicadores de saúde dos 121 municípios fronteiriços abarcados pela política em comparaçáo com os 467 demais municípios da FF não beneficiados pelo projeto, usando-se as técnicas Propensity Score Matching e Diferenças em Diferenças. Segundo, para compreender a dinâmica de implantação do projeto, foram analisadas entrevistas em profundidade e workshops com um total de 227 informantes-chave utilizando-se a análise de conteúdo.

Os resultados revelam que o impacto nos indicadores foi limitado, ainda que o volume de recursos investidos tenha sido considerável. Os municípios incluídos no projeto não apresentaram melhoras significativas, diferente dos demais nos indicadores analisados. Suas descobertas sugerem que a inadequação do uso dos recursos às características da fronteira explica a falha em alavancar as condições de saúde nessas áreas, sendo gerados, ainda, insights para informar futuras políticas de saúde nessas e em outras áreas. Tais açôes poderiam oportunizar melhores resultados no contexto de políticas públicas fronteiriças em geral, entre elas: cooperaçáo para disposição de serviços, dimensionamento da demanda, investimentos, desburocratização, amparo legal, estratégias de longo prazo, continuidade política e accountability.

A partir dos resultados do primeiro estudo em análise, percebe-se a necessidade de governança em áreas de fronteira. Isso porque, como já apontado, a governança transfronteiriça tem sido percebida como a necessidade de coordenação de políticas ou de gerenciamento de interdependências transfronteiriças para o alcance de melhores resultados. Contudo, há claramente uma falta de estudos que discutam de uma forma mais abrangente os elementos limitantes ou potencializadores desse processo, denominados, no âmbito da tese em resenha, fatores críticos.

O segundo estudo em análise, portanto, teve por objetivo desenvolver um modelo a partir da visão integrada acerca da literatura de governança transfronteiriça, levantando os fatores críticos identificados na literatura analisada. Para isso, foram coletados, categorizados e analisados trinta artigos provenientes das bases Scopus e Web of Science. Concluiu-se que a temática é recente, com estudos de abordagem qualitativa e concentrados nas fronteiras da Europa. A partir da sistematização da literatura, houve a construção do modelo que dispóe os fatores críticos da governança transfronteiriça (FCGTs), sintetizados nas dimensôes 
territorial, recursos, institucional e político-regulatória, finalizando na proposição de uma agenda de estudos futuros com sugestóes de pesquisas.

Consequentemente, em virtude de múltiplos desafios que engendram esse decurso e a falta de reflexáo acadêmica na literatura gerencial sobre o fenômeno, o terceiro estudo em análise objetivou examinar a aplicabilidade do modelo FCGT (proposto no segundo estudo da tese em resenha), buscando levantar contribuiçôes gerenciais no processo. Para o alcance do objetivo de estudo, foram realizadas entrevistas com dois grupos de interesse: especialistas europeus e brasileiros, por se apresentarem contextualmente relevantes no tema. Isso porque a literatura tem apontado que a análise de peritos de diferentes áreas geográficas e de know-how distintos, em cruzamento, pode enriquecer o fomento do quadro de conhecimentos comuns.

Com esse propósito, as falas dos especialistas foram gravadas, transcritas e analisadas com o auxílio do software NVivo. Os resultados demonstram que todos os componentes do modelo são aplicáveis às duas realidades, evidenciando-se, ainda, elementos complementares que contribuem para o aperfeiçoamento da sua estrutura, estratégias gerenciais e gaps a serem superados para se construir caminhos em meio aos obstáculos da governança em áreas de fronteira. As contribuições teóricas estão no aperfeiçoamento do modelo FCGT, até o momento ainda não abordado em estudos acadêmicos, e as implicaçóes práticas estão na disposição de um constructo que, em sua adoção, os gestores poderão entender e melhor gerir os componentes críticos do processo. O quadro 1 sintetiza os gaps teóricos demonstrados pela literatura a respeito do tema e as contribuiçóes e limitaçôes dos estudos em análise multinível.

A partir da análise multinível dos estudos em tela, desenvolveram-se reflexôes e propostas de estudos futuros. Primeiramente, a partir da avalição do Projeto SIS-Fronteiras, reflete-se a necessidade de estudo acerca da gestão de políticas públicas fronteiriças para a busca de novas estratégias de coordenação e governança, visto que os resultados de uma política podem estar estritamente relacionados à sua customizaçáo em relação às características territoriais e ao modo que seus recursos foram geridos e aplicados (Krüger, 2019).

Por sua vez, a análise da proposta de um modelo FCGT salientou quatro elementos norteadores: i) pesquisas com abordagens teórico-práticas, verificando a aplicabilidade do framework proposto com especialistas e análises em diferentes territórios; ii) considerar governança transfronteiriça em outros territórios, incluindo a difusão da temática na produção sul-americana e científica no Brasil; iii) levantamento e sistematização dos grupos de pesquisa e projetos interinstitucionais para fortalecer a cooperação entre diferentes instituiçôes de ensino e pesquisa nas discussóes sobre governança em fronteiras; e iv) produzir estudos quantitativos e com métodos mistos que utilizem diferentes atores da governança transfronteiriça para apontar as principais variáveis nesse processo e sua ordem de importância ao afetar diferentes áreas, como saúde, educação, meio ambiente, economia, turismo, entre outras.

Por fim, na análise do estudo que examina a aplicabilidade do modelo FCGT percebe-se a necessidade de pesquisas com especialistas de outras regióes fronteiriças do país e do mundo, visando subsidiar proposiçóes de ferramentas gerenciais para a tomada de decisóes ante o tema. 
QUADRO 1

Gaps teóricos, contribuições e limitações dos ensaios em análise multinível

\begin{tabular}{|c|c|c|}
\hline Gaps teóricos & Contribuições & Limitações \\
\hline $\begin{array}{l}\text { a) Carência de monitoramento e } \\
\text { avaliação das políticas públicas } \\
\text { fronteiriças (Brasil, 2016b; Krüger } \\
\text { et al., 2017). } \\
\text { b) Falta de disposição de dados } \\
\text { oficiais para avaliação (Krüger } \\
\text { et al., 2017). } \\
\text { c) Falta de transparência na } \\
\text { disposição de informações (Krüger, } \\
\text { Dantas e Castro, 2018). }\end{array}$ & $\begin{array}{l}\text { a) Contribuição teórica pelo levantamento } \\
\text { de bases conceituais relativas à avaliação de } \\
\text { políticas públicas aplicáveis ao contexto da } \\
\text { gestão fronteiriça. } \\
\text { b) Contribuição metodológica pela proposição de } \\
\text { um modelo de avaliação para políticas públicas } \\
\text { de saúde, que pode ser expandido para avaliar } \\
\text { políticas públicas em outras áreas, a partir da } \\
\text { troca das variáveis em análise e das bases de } \\
\text { dados utilizadas. } \\
\text { c) Contribuição empírica pela avaliação de um } \\
\text { projeto ainda não avaliado na totalidade de } \\
\text { municípios por ele abrangidos, instrumentalizando } \\
\text { a gestão pública para ações não só na saúde em } \\
\text { região de fronteira, mas também podendo ser } \\
\text { estendida a outras áreas. }\end{array}$ & $\begin{array}{l}\text { a) Avaliação de política pública única, } \\
\text { com limitada validade para o conjunto } \\
\text { de políticas públicas fronteiriças. Porém, } \\
\text { essa estratégia de pesquisa foi a mais } \\
\text { adequada, tendo em vista os dados } \\
\text { públicos oficiais disponíveis. } \\
\text { b) Característica de corte transversal do } \\
\text { estudo, que fornece apenas uma parte da } \\
\text { imagem da heterogeneidade das políticas } \\
\text { públicas fronteiriças. } \\
\text { c) Apesar de os resultados não } \\
\text { permitirem a generalização estatística } \\
\text { em relação ao impacto da avaliação } \\
\text { em cada município participante do } \\
\text { projeto, os dados possibilitam uma } \\
\text { generalização analítica. }\end{array}$ \\
\hline $\begin{array}{l}\text { a) Falta de estudos que abordem de } \\
\text { uma forma abrangente os elementos } \\
\text { limitantes ou potencializadores } \\
\text { (Mikhailova, 2014). } \\
\text { b) A literatura sobre o tema } \\
\text { tem demonstrado polissemia } \\
\text { problemática do termo } \\
\text { (Dupeyron, 2017). } \\
\text { c) Carência de revisões sistemáticas } \\
\text { que sintetizem os resultados dos } \\
\text { estudos já realizados (Mikhailova, } \\
\text { 2014; Pikner, 2008; Schmidt, 2005). }\end{array}$ & $\begin{array}{l}\text { a) Contribuição teórica pelo levantamento e } \\
\text { análise crítica da literatura existente sobre } \\
\text { governança transfronteiriça. } \\
\text { b) Contribuição metodológica pela síntese da } \\
\text { literatura, análise e codificação de variáveis } \\
\text { salutares para análise dos fatores críticos para a } \\
\text { governança em âmbito transfronteiriço. } \\
\text { c) Contribuição empírica pela síntese dos fatores } \\
\text { críticos levantados na literatura em um framework } \\
\text { de análise para governança transfronteiriça } \\
\text { sistematizado nas dimensões e componentes } \\
\text { elementares no processo. }\end{array}$ & $\begin{array}{l}\text { a) Pesquisa de caráter exploratório; } \\
\text { portanto, o uso exclusivo das bases de } \\
\text { referências selecionadas, assim como } \\
\text { a escolha das palavras-chave e os } \\
\text { critérios de inclusão e exclusão, pode ter } \\
\text { influenciado a quantidade limitada de } \\
\text { estudos identificados sobre o tema. }\end{array}$ \\
\hline $\begin{array}{l}\text { a) Falta de perspectivas práticas } \\
\text { que vão além de pesquisas com } \\
\text { abordagens específicas do processo } \\
\text { (Deppisch, 2012; Hernández- } \\
\text { Ramírez, 2017). } \\
\text { b) Ou estudos de caso } \\
\text { (Evrard, 2016; Spacek, 2018; } \\
\text { Svensson, 2015). }\end{array}$ & $\begin{array}{l}\text { a) Contribuições teóricas pelo aperfeiçoamento } \\
\text { do modelo FCGT, até o momento ainda não } \\
\text { abordado em estudos acadêmicos. } \\
\text { b) Contribuição metodológica pela geração de } \\
\text { um quadro de referência quanto às principais } \\
\text { similaridades e diferenciações das opiniões dos } \\
\text { especialistas brasileiros e europeus envolvidos } \\
\text { com o tema da governança nesses territórios. } \\
\text { c) Contribuição empírica pela disposição de um } \\
\text { constructo que, em sua adoção, os gestores } \\
\text { poderão entender e melhor gerir os componentes } \\
\text { críticos do processo. }\end{array}$ & $\begin{array}{l}\text { a) Em função de os especialistas } \\
\text { entrevistados serem de dois contextos } \\
\text { territoriais, suas visões sobre o tema } \\
\text { possuem reflexos de suas vivências e } \\
\text { experiências nas localidades. }\end{array}$ \\
\hline
\end{tabular}

Elaboração dos autores.

\section{CONSIDERAÇÕES FINAIS}

Depreende-se que a tese em resenha neste ensaio chega a resultados exitosos quando se retoma o objetivo geral do estudo, cujos resultados não seriam possíveis sem a abertura e o apoio de instituiçóes relevantes e atores-chave que se dispuseram a prestar dados e informaçóes a respeito das fronteiras do Brasil e da Europa. Entre as instituições em pauta, a participação da autora da tese (Caroline Krüger) como bolsista no Ipea, no projeto A Política Nacional de Desenvolvimento Regional (PNDR) e a Faixa de Fronteira, fez-se fundamental para o aprofundamento do tema, dado que, por meio da pesquisa citada, percebem-se as lacunas que a tese em tela se propóe a preencher.

Assim, este ensaio contribui ao realizar uma análise multinível dos três estudos que formaram a tese em tela, corroborando por meio de uma revisão da literatura e ascendendo às seguintes conclusões: primeiramente, o cenário que motivou tal ensejo de contribuição - as fronteiras - são ambientes extremamente dinâmicos e criativos, mais cosmopolitas e tolerantes 
(Oliveira e Dorfman, 2015), porém, permeado de desafios, dada a sua conjuntura cultural, política e institucional, que proporciona análises ignorantes da mídia, conhecimentos controversos da população e intervençóes repressoras do Estado (Dupeyron, 2017; Hernández-Ramírez, 2017), fazendo com que pesquisas propositivas nessa pauta sejam fundamentais (Pêgo et al., 2017; 2018; 2020a).

Outro ponto se refere às mudanças de perspectivas sobre o tema, uma vez que as fronteiras mundiais, de forma geral, passam por um período de intensa mutabilidade, cujos fatores exógenos têm afetado profundamente suas relaçóes internas (Cruz, 2014), materializando-se por meio de um processo de fechamento seletivo (Oliveira e Dorfman, 2015; Pêgo et al., 2020b) em nome da securitização, que guarda raízes nas desigualdades sociais (Kramsch, 2002), separando povos em sua maioria, com intensas relaçóes de cooperação e integração cotidianas (Oliveira, 2015).

As fronteiras na Europa, a exemplo, permeadas de incentivos à cooperação transfronteiriça, com acordos construídos principalmente desde o pós-guerra, que reverberaram em açôes para integrar países que estiveram em conflito, passam por desafios ao implementar paradigmas "importados", sem análises mais aprofundadas das relaçóes históricas e reais necessidades locais de cada fronteira pertencente ao continente (Leibenath, 2007).

Além disso, na atualidade, tem ocorrido um processo de burocratização com a implementação de diretrizes rigorosas e detalhadas no Interreg, ${ }^{11}$ resultando em um esvaziamento do envolvimento de novos recursos humanos não estatais (Zäch e Pütz, 2014). Ainda, diante do fechamento de fronteiras, justificado por atentados, crises imigratórias e pandemias (Pêgo et al., 2020b), que reverberam em diferentes posicionamentos e desacordos entre os países-membros, a União Europeia tem buscado novos caminhos para a manutenção da sua política transfronteiriça (Oddone, Vázquez e Oro, 2018).

Percebe-se ainda que no Brasil, especificamente, as fronteiras passaram por um processo de transformação da sua concepção, que inicialmente estava pautado como área tampão, fundamentado na preocupação do Estado com a garantia de sua soberania, e açóes restritas a "segurança, controle e proteção", que limitavam as oportunidades de desenvolvimento local, passando a ser vistas como um espaço dotado de complexidade e peculiaridades que as tornava singular em relação ao restante do país, com necessidade de ações diferenciadas para integração e desenvolvimento (Brasil, 2005; 2016a; Krüger, 2019).

Por fim, é importante ressaltar que, mesmo com essas iniciativas, há uma permanência do princípio da segurança sobrepondo-se ao da mobilidade; os projetos são descontinuados, perdendo-se os elementos positivos obtidos; há uma negligência com a integração de açôes se materializando na falta de articulação (Krüger, 2019). Esse cenário demonstra a necessidade de programas de desenvolvimento permanentes, a legalização de aparato jurídico que promova ferramentas e independência locais para açôes integradas nos territórios, visando a uma efetiva governança transfronteiriça (Henrichs e Meza, 2017).

11. Insere-se como um conjunto de programas para o estímulo à cooperação entre as regiões da União Europeia (Evrard, 2016). 


\section{REFERÊNCIAS}

ACNUR - ALTO COMISSARIADO DAS NAÇÓES UNIDAS PARA OS REFUGIADOS. Protegendo refugiados no Brasil e no mundo. 2019. Disponível em: <https://www.acnur.org/ portugues/wp-content/uploads/2019/02/CARTILHA-ACNUR2019.pdf.> Acesso em: 27 ago. 2019.

AGUINIS, H.; GOTTFREDSON, R.; CULPEPPER, S. Best-practice recommendations for estimating cross-level interaction effects using multilevel modeling. Journal of Management, v. 39, n. 6, p. 1490-1528, 2013.

BRASIL. Ministério da Integraçâo Nacional. Proposta de reestruturaçáo do Programa de Desenvolvimento da Faixa de Fronteira. Brasília, DF: Ministério da Integração Nacional, 2005.

Ministério da Integração Nacional. Faixa de Fronteira: programa de promoção do desenvolvimento da Faixa de Fronteira. Brasília, DF: Ministério da Integração Nacional, 2009.

Ministério da Integração Nacional. Grupo de Trabalho Interfederativo de Integração Fronteiriça (GTIIF). Bases para uma proposta de desenvolvimento e integraçáo da Faixa de Fronteira. Brasília, DF: GTIIF, 2010.

Constituição (1988). Constituição da República Federativa do Brasil: texto constitucional promulgado em 5 de outubro de 1988, com as alteraçôes determinadas pelas Emendas Constitucionais de Revisão 1 a 6/94, pelas Emendas Constitucionais 1/92 a 91/2016 e pelo Decreto Legislativo no 186/2008. Brasília, DF: Senado Federal, 2016a.

Ministério da Justiça. Mapeamento das políticas públicas federais na Faixa de Fronteira: interfaces com o plano estratégico de fronteiras e a estratégia nacional de segurança pública nas fronteiras. Brasília, DF: Ministério da Justiça, $2016 \mathrm{~b}$.

Ministério da Integração Nacional. Portaria no 213, de 19 de julho de 2016. Estabelece o conceito de "cidades gêmeas" nacionais, os critérios adotados para essa definição e lista todas as cidades brasileiras por estado que se enquadram nesta condição. Diário Oficial da União, Brasília, 20 jul. 2016c. Disponível em: <https:/www.diariodasleis.com.br/legislacao/federal/226680-conceito-decidades-gumeas-nacionais-os-criturios-adotados-para-essa-definiuuo-estabelece-o-conceito-de-cidadesgumeas-nacionais-os-criturios-adotados-para-essa-definiuuo-e-li.html>. Acesso em: 27 ago. 2019.

CARGNIN, A. P. Política nacional de desenvolvimento regional e repercussóes no Rio Grande do Sul. Mercator, Fortaleza, v. 13, n. 1, p. 19-35, jan./abr. 2014.

CRUZ, P. Cross-border governance on the U.S. - Mexico border: institutional challenges and developments in health collaboration. Regions \& Cohesion, New York, v. 4, n. 1, p. 53-71, 2014.

DEPPISCH, S. Governance processes in Euregios. Evidence from six cases across the Austrian-German border. Planning Practice \& Research, London, v. 27, n. 3, p. 315-332, 2012.

DOOCY, S. et al. Venezuelan migration and the border health crisis in Colombia and Brazil. Journal on Migration and Human Security, Thousand Oaks, Aug. 2019. Disponível em: $<$ https://journals.sagepub.com/doi/full/10.1177/2331502419860138>. Acesso em: 27 ago. 2019.

DUPEYRON, B. 'Secondary foreign policy' through the prism of cross-border governance in the US-Canada Pacific Northwest border region. Regional \& Federal Studies, London, v. 27, n. 3, p. 321-340, 2017.

DURAND, F.; NELLES, J. Binding cross-border regions: analysis of cross-border governance in Lille-Kortrijk-Tournai Eurometropolis. Tijdschrift voor Economische Sociale Geografie, Hoboken, v. 105, n. 5, p. 1-18, 2014. 
EVRARD, E. The European Grouping of Territorial Cooperation (EGTC): towards a supraregional scale of governance in the greater Region SaarLorLux? Geopolitics, London, v. 21, n. 3, p. 513-537, 2016.

FOUCHER, M. Obsessão por fronteiras. Tradução Cecília Lopes. São Paulo: Radical Livros, 2009.

GEREFFI, G. The global economy: organization, governance, and development. In: SMELSER, N. J.; SWEDBERG, R. The handbook of economic sociology. 2. ed. New York: Princeton University Press, 2005.

GIMENEZ, H. M. Defesa nacional, segurança pública e relaçóes internacionais: uma análise sobre a fronteira Bolívia-Brasil (2005-2014). 2015. 2 v. Tese (Doutorado) -Universidade de Brasília, Brasília, DF, 2015.

GTSCA2030 - GRUPO DE TRABALHO DA SOCIEDADE CIVIL PARA A AGENDA 2030. III Relatório Luz da Sociedade Civil da Agenda 2030 para o Desenvolvimento Sustentável, 2019. Disponível em: <https://www.geledes.org.br/wp-content/uploads/2019/08/ relatorio_luz_portugues_19_download_v3.pdf>. Acesso em: 9ago. 2019.

GUALINI, E. Cross-border governance: inventing regions in a trans-national multi-level polity. disP - The Planning Review, London, v. 39, n. 152, p. 43-53, 2003.

HENRICHS, J. A.; MEZA, M. L. F. G. Governança multinível para o desenvolvimento regional: um estudo de caso do Consórcio Intermunicipal da Fronteira. Urbe, Revista Brasileira de Gestáo Urbana, Curitiba, v. 9, n. 1, p. 124-138, 2017. Disponível em: <http://www.scielo.br/ scielo.php?script $=$ sci_arttext\&pid=S2175-33692017000100124\&lng=en\&nrm=iso $>$. Acesso em: 19 fev. 2019.

HERNÁNDEZ-RAMÍREZ, J. Obstáculos a la gobernanza turística en la frontera del Bajo Guadiana. Investigaciones Turísticas, Santa Cruz de Tenerife, v. 13, p. 140-163, 2017.

IBGE - INSTITUTO BRASILEIRO DE GEOGRAFIA E ESTATÍSTICA. Municípios da faixa de fronteira. Rio de Janeiro: IBGE, 2018. Disponível em: <https:/www.ibge.gov.br/ geociencias/organizacao-do-territorio/estrutura-territorial/24073-municipios-da-faixa-de-fronteira. html?=\&t=o-que-e>. Acesso em: 23 out. 2019.

Estimativas da populaçáo residente no Brasil e Unidades da Federaçáo com data de referência em $1^{\circ}$ de julho de 2019. Diretoria de Pesquisas - DPE; Coordenação de População e Indicadores Sociais - COPIS, 2019. Disponível em: <https://agenciadenoticias.ibge.gov.br/ media/com_mediaibge/arquivos/42ff76cf13a382a709c1ba14214b8612.pdf $>$. Acesso em: 27 jan. 2020.

JOBERT, B.; MULLER, P. L'Etatenaction: politiques publiques et corporatismes. Paris: PUF, 1987.

KRAMSCH, O. T. Reimagining the scalar topologies of cross-border governance: $\mathrm{Eu}(\mathrm{ro})$ regions in the post-colonial present. Space and Polity, London, v. 6, n. 2, p. 169-196, 2002.

KRÜGER, C. Da avaliaçáo de impacto à governança transfronteiriça: contribuiçōes para o aperfeiçoamento da gestáo de políticas públicas. 2019. Tese (Doutorado) - Faculdade de Economia, Administração e Contabilidade de Ribeirão Preto, Universidade de Sáo Paulo, Ribeirão Preto, 2019.

KRÜGER, C.; DANTAS, M.; CASTRO, M. Políticas públicas e desenvolvimento: uma análise aplicada ao contexto da faixa de fronteira no Brasil. In: PÊGO, B.; MOURA, R. (Org.). Fronteiras do Brasil: uma avaliaçấo de política pública. Rio de Janeiro: Ipea/MI, 2018. p. 325-350. 
KRÜGER, C. et al. Análise das políticas públicas para o desenvolvimento da faixa de fronteira brasileira. Ambiente e Sociedade, São Paulo, v. 20, n. 4, p. 39-70, 2017.

LEIBENATH, M. Europeanisation of cross-border governance? A case study on the cause, form and consequences of a co-operation project in the German-Polish-Czech Border Triangle. Space and Polity, London, v. 11, n. 2, p. 151-167, 2007.

MACHADO, L. Ciência, tecnologia e desenvolvimento regional na faixa de fronteira do Brasil. Parcerias Estratégicas, Brasília, DF, n. 20, p. 1-554, jun. 2005. (Edição especial).

MIKHAILOVA, E. V. Theorizing on cross-border governance: from emergence of the concept to its current understanding. Public Administration E-Jornal, Moscow, n. 46, p. 51-66, 2014.

NAÇÓES UNIDAS BRASIL. Transformando nosso mundo: a Agenda 2030 para o desenvolvimento sustentável. 2015. Disponível em: <http://nacoesunidas.org/pos2015/ agenda2030/>. Acesso em: 9 ago. 2019.

ODDONE, N.; VÁZQUEZ, H.; ORO, M. Paradiplomacia local y transfronteriza como un instrumento de gobernanza ambiental en el Mercosur y la Unión Europea: una descripción comparada. Civitas - Revista de Ciências Sociais, Porto Alegre, v. 18, n. 2, p. 332-350, 2018.

OLIVEIRA, T. C. M. Para além das linhas coloridas ou pontilhadas - reflexões para uma tipologia das relaçóes fronteiriças. Revista da Associaçáo Nacional de Pós-Graduaçáo e Pesquisa em Geografia (Anpege), v. 11, n. 15, p. 233-256, 2015. Disponível em: <http://ojs.ufgd.edu.br/ index.php/anpege/article/view/6454/3400>. Acesso em: 31 out. 2019.

OLIVEIRA, T. C. M.; DORFMAN, A. Vivemos um processo de fechamento seletivo de fronteiras no mundo. 2015. Disponível em: <https://www.sul21.com.br/entrevistas-2/2015/11/ vivemos-um-processo-de-fechamento-seletivo-de-fronteiras-no-mundo-dizem-pesquisadores $>$. Acesso em: 31 out. 2019.

PÊGO, B. et al. Fronteiras do Brasil: diagnóstico e agenda de pesquisa para política pública. Rio de Janeiro: Ipea/MI, 2017. v. 2.

PÊGO, B. et al. Fronteiras do Brasil: uma avaliação do arco Norte. Rio de Janeiro: Ipea/MI, 2018. v. 3 .

PÊGO, B. et al. Fronteiras do Brasil: uma avaliaçấo do arco Sul. Rio de Janeiro: Ipea/MI, 2020a. v. 5 .

PÊGO, B. et al. Pandemia e fronteiras brasileiras: análise da evoluçâo da Covid-19 e proposições. Brasília: Ipea, 2020b.

PÊGO, B.; MOURA, R.; NUNES, M. Interaçôes entre Cáceres (Mato Grosso) e San Matías (Bolívia): a pertinência de uma nova cidade gêmea brasileira. Boletim Regional, Urbano e Ambiental, Brasília: Ipea, v. 21, n. 2, p. 39-47, 2019.

PERKMANN, M. Policy entrepreneurship and multilevel governance: a comparative study of European cross-border regions. Environment and Planning C: Government and Policy, v. 25, n. 6, p. 861-879, 2007. Disponível em: <https://doi.org/10.1068/c60m>.

PIKNER, T. Reorganizing cross-border governance capacity the case of the Helsinki-Tallinn Euregio. European Urban and Regional Studies, London, v. 15, n. 3, p. 211-227, 2008.

SCHERMA, M. A. As políticas brasileiras para a faixa de fronteira: um olhar a partir das relaçōes internacionais. 2015. 272 f. Tese (Doutorado) - Universidade Estadual de Campinas, Campinas, 2015. 
SCHMIDT, T. Cross-border regional enlargement in Øresund. GeoJournal, Berlin, v. 64, n. 3, p. 249-258, 2005.

SCOTT, J. W. Euroregions, governance and transborder cooperation within the EU. In: VAN DER VELDE, M.; VAN HOUTUM, H. (Ed.). Borders, border regions and people. London: Pion, 2000. p. 91-106.

ŠPAČEK, M. Multilevel cross-border governance in the Czech-Saxon borderland: working together or in parallel? Administrative Culture, Tallinn, v. 18, n. 2, p. 175-202, 2018.

SVENSSON, L. E. O. The possible unemployment cost of average inflation below a credible target. American Economic Journal: Macroeconomics, Nashville, v. 7, n. 1, p. 258-296, 2015.

TORRECILHA, M. L. A gestáo compartilhada como espaço de integraçáo na Fronteira Ponta Porã (Brasil) e Pedro Juan Caballero (Paraguai). 2013. 180 f. Tese (Doutorado) Faculdade de Filosofia, Letras e Ciências Humanas, Universidade de São Paulo, São Paulo, 2013.

ZÄCH, C.; PÜTZ, M. Regional governance in der grenzüberschreitenden Zusammenarbeit. disP - The Planning Review, London, v. 50, n. 4, p. 29-42, 2014.

ZUMBUSCH, K.; SCHERER, R. Cross-border governance: balancing formalized and less formalized co-operations. Social Sciences, Basel, v. 4, n. 3, p. 499-519, 2015.

\section{BIBLIOGRAFIA COMPLEMENTAR}

DESCHAMPS, M.; DELGADO, P.; MOURA, R Mobilidade pendular na faixa de fronteira brasileira: particularidades dos arranjos transfronteiriços. In: PÊGO, B.; MOURA, R. (Org.). Fronteiras do Brasil: uma avaliação de política pública. Rio de Janeiro: Ipea/MI, p. 293-316, 2018.

PERKMANN, M.; SUM, N. Globalization, regionalization and cross-border regions: scales, discourses and governance. In: PERKMANN, M.; SUM, N. (Ed.). Globalization, regionalization and cross-border regions. London: Palgrave Macmillan, p. 3-21, 2002. 